\title{
PERAN KARAKTER AUDITOR TERHADAP KUALITAS AUDIT
}

\author{
Ni Nyoman Ayu Suryandari ${ }^{1}$, I Dewa Made Endiana ${ }^{2 *}$ \\ ${ }^{1,2}$ Universitas Mahasaraswati Denpasar \\ *e-mail: a.suryandari@ymail.com
}

DiPublikasi: 01/07/2021

https://doi.org/10.22225/kr.13.1.2021.113-121

\begin{abstract}
Users of financial statements rely on the services of a public accounting firm in assessing the reliability of a company's financial statements because it is impossible for users to check the financial statements of every company. Public Accounting Firm is a service business that is believed to have the ability to bridge the interests of the company with stakeholders. This trust requires auditors to be able to conduct audits that are free and impartial in order to produce good audit quality. As a result of the research gap from previous researchers, this study uses a moderating variable in the form of auditor ethics. This study aims to prove the effect of an auditor's competence and independence on audit quality with auditor ethics as a moderating variable. The population in this study were all auditors who worked at public accounting firms in Bali, namely 13 public accounting firms with a sample of 93 respondents with the criteria of respondents being at least one year of work experience. There are 41 questionnaires used in the data analysis. The analysis technique used in this research is Moderated Regression Analysis. The results of this study prove that: (1) the competence of an auditor is able to play a role in improving audit quality. (2) the independence of an auditor does not play a role in improving audit quality. (3) auditor ethics cannot moderate the relationship between auditor competence and audit quality. (4) auditor ethics also cannot moderate the relationship between auditor independence and audit quality.
\end{abstract}

Keywords: audit quality, competence, independence and ethic

\section{Abstrak}

Pemakai laporan keuangan mengandalkan jasa Kantor Akuntan Publik dalam menilai keandalan laporan keuangan suatu perusahaan karena tidak mungkin pemakai melakukan pemeriksaan terhadap laporan keuangan di setiap perusahaan. Kantor Akuntan Publik adalah suatu usaha jasa yang diyakini mempunyai kemampuan dalam menjembatani kepentingan perusahaan dengan stakeholder. Kepercayaan tersebut menuntut auditor untuk dapat melakukan audit yang bebas dan tidak memihak agar menghasilkan kualitas audit yang baik. Akibat adanya research gap dari peneliti terdahulu maka penelitian ini menggunakan variabel moderasi berupa etika auditor. Penelitian ini bertujuan untuk membuktikan pengaruh kompetensi dan independensi seorang auditor terhadap kualitas auditnya dengan etika auditor sebagai variabel moderasi. Populasi dalam penelitian ini adalah seluruh auditor yang bekerja pada Kantor Akuntan Publik di Bali yaitu 13 Kantor Akuntan Publik dengan sampel 93 responden dengan kriteria responden adalah berpengalaman kerja minimal satu tahun. Kuesioner yang digunakan dalam analisis data berjumlah 41 kuesioner. Teknik analisis yang digunakan dalam penelitian ini adalah Moderated Regression Analysis. Hasil penelitian ini membuktikan bahwa: (1) kompetensi seorang auditor mampu berperan meningkatkan kualitas audit. (2) independensi seorang auditor tidak berperan dalam meningkatkan kualitas audit. (3) etika auditor tidak dapat memoderasi hubungan kompetensi auditor dan kualitas audit. (4) etika auditor juga tidak dapat memoderasi hubungan antara independensi auditor dan kualitas audit.

Kata Kunci : Audit report lag, ukuran perusahaan, profitabilitas, solvabilitas, kualitas audit, opini audit, audit

\section{PENDAHULUAN}

Para pemakai laporan keuangan akan selalu mempertanyakan keandalan laporan keuangan dari suatu perusahaan sebelum mereka membuat suatu keputusan, dan sangat tidak mungkin jika setiap pengguna laporan keuangan melakukan pemeriksaan untuk mengetahui keandalan laporan keuangan. Cara umum yang dilakukan para stakeholder dalam mengetahui keandalan laporan keuangan adalah dengan meminta pihak sebelum laporan keuangan tersebut dipublikasikan kepada para stakeholder. Kantor akuntan publik independent dalam memeriksa laporan keuangan

selama ini berfungsi sebagai jembatan penghubung antara perusahaan dan pengguna laporan keuangan. Dengan adanya audit atas laporan keuangan dari jasa yang diberikan oleh kantor akuntan publik maka diharapkan kepercayaan pengguna laporan keuangan akan semakin meningkat. Begitu besarnya peranan laporan keuangan dalam pengambilan keputusan stakeholder maka laporan keuangan menjadi sorotan yang sangat tajam. Laporan keuangan mungkin saja telah sengaja dimanipulasi oleh pihak manajemen dengan tujuantujuan untuk kepentingan mereka ataupun Jurnal KRISNA: Kumpulan Riset Akuntansi Volume 13, Nomor 12021 CC-BY-SA 4.0 License
Page 113 
mengandung salah saji akibat ketidaksengajaan. Dalam praktiknya, profesi akuntan publik cukup sering mendapatkan sorotan publik terkait dengan keterlibatannya dalam kasus pelanggaran karena terbukti menghasilkan laporan audit yang menyebabkan sesatnya keputusan yang diambil oleh pengguna laporan keuangan. Salah satu kasus pelanggaran yang melibatkan akuntan publik yaitu pada kasus PT Garuda Indonesia. Perusahaan mengakui pendapatan sebelum terealisasi sehingga menghasilkan laporan keuangan yang menunjukan keuntungan tinggi sementara pada periode sebelumnya, perusahaan masih mengalami kerugian. Akuntan publik yang melakukan audit atas laporan keuangan perusahaan tersebut yaitu Kasner Sirumapea diberikan sanksi oleh Menteri Keuangan berupa Pembekuan Izin selama 12 bulan (KMK No.312/KM.1/2019 tanggal 27 Juni 2019) karena melakukan pelanggaran berat yang berpotensi mempengaruhi opini audit yang diberikan. Kasus tersebut menjadi salah satu dari kasus kecurangan yang dilakukan oleh akuntan publik yang kemudian menimbulkan pertanyaan di masyarakat tentang keandalan profesi auditor. Banyak faktor yang dibutuhkan auditor untuk menghasilkan audit yang berkualitas. Oleh karena peran akuntan publik yang begitu besar maka perlu juga diperhatikan terkait dengan karakter dari akuntan publik itu sendiri agar dapat menghasilkan audit yang berkualitas. Karakter yang dimaksud

\section{TINJAUAN PUSTAKA}

Penelitian ini menggunakan teori keagenan sebagai teori utama. Menurut (Jensen \& Meckling, 1976) teori keagenan (Agency Theory) adalah suatu kontrak yang melibatkan agen untuk melaksanakan beberapa layanan dengan melakukan pendelegasian wewenang pengambilan keputusan dari principles. Teori agensi (Agency Theory) mengasumsikan bahwa individu bertindak memaksimalkan kepentingan sendiri sehingga dengan informasi yang dimilikinya akan terdorong untuk menyembunyikan beberapa informasi yang tidak diketahui principal. Pihak ketiga merupakan media independen sebagai mediator pada hubungan antara principal dan agen. Pihak ketiga berfungsi untuk memantau kesesuaian perilaku manajer (agen) dengan keinginan pemilik (principal). Jadi, kehadiran auditor berperan dalam teori keagenan, yaitu sebagai penengah antara principal dan agen melalui proses audit terhadap laporan keuangan diantaranya adalah kompeten dan independen. Kompeten dapat diartikan sebagai kemampuan dalam mengerjakan suatu tugas audit dengan menggunakan pengetahuan, keahlian dan pengalamannya. Kompetensi amatlah penting bagi auditor karena konpetensi akan menentukan tingkah laku auditor dan tingah laku akan mempengaruhi kinerja dari seorang auditor (Dewana, 2015) sedangkan independen yaitu mandiri dan terpisah dari berbagai kegiatan yang diperiksa. Independensi sangat penting karena pemeriksaan dari auditor yang independen sangat dibutuhkan agar laporan keuangan semakin dapat dipercaya oleh pemakai laporan keuangan karena auditor tidak memiliki kepentingan terhadap perusahaan. Independensi disini yang dimaksudkan adalah independensi secara fakta, independensi secara penampilan dan independensi secara kompetensi.

Tidak konsistennya penelitian sebelumnya terkait pengaruh kompetensi dan independensi maka mungkin saja ada faktor lain yang mempengaruhi auditor dalam berkinerja terkait dengan kualitas audit yang dihasilkannya. Sehingga digunakanlah etika auditor sebagai variabel moderasi dalam penelitian ini. Etika auditor berarti bagaimana auditor mampu bekerja sesuai dengan kode etik organisasinya.

yang disajikan agen. Proses audit yang dilaksanakan oleh auditor harus berkualitas agar stakeholder mampu menggunakan informasi tersebut dalam pengambilan keputusan.

\section{Peran Kompetensi Auditor pada Kualitas Audit}

Kompetensi adalah karakter utama yang harus dimiliki oleh seorang auditor (Abdelmoula, 2020). Kompeten berarti auditor memiliki pengetahuan, keahlian dan berpengalaman. Kompetensi dalam penelitian ini diukur dengan pengetahuan dan psikologi. Auditor harus memiliki pendidikan formal, memiliki pengalaman mengaudit, kreatif dalam menyelesaikan suatu masalah, mencari bukti-bukti audit sampai akarnya, melaksanakan audit sesuai dengan standar dan mampu bekerjasama dalam teamwork. Peningkatan kompetensi auditor bisa dalam hal pemahaman terkait isu dan aturan terkini. Dengan kompetensi 
yang dimiliki, seorang auditor menjadi lebih dipercaya dan dianggap mampu dalam menjalankan tugasnya, sehingga akan meningkatkan kualitas dalam mengaudit. Kualitas audit dapat diartikan sebagai probabilitas auditor dalam menemukan dan melaporkan salah saji dan kecurangan yang terjadi dalam keuangan klien. Hal ini sejalan dengan hasil penelitian (Farida et al., 2016; Mutiara, 2018; Nurjanah \& Kartika, 2016; Wardhatul et al., 2019). Berdasarkan penjelasan di atas, dapat disimpulkan hipotesis :

$\mathrm{H}_{1}$ : Kompetensi berpengaruh positif terhadap kualitas audit

\section{Peran Independensi Auditor pada Kualitas Audit}

Independensi berarti sikap tidak memihak, baik dari segi menguji, mengevaluasi atau dari segi menyusun laporan audit. Auditor wajib dapat melaporan apa yang menjadi kondisi senyatanya di lapangan. Independensi dalam penelitian ini diukur dengan lama hubungan dengan klien, tekanan klien, telaah dari rekan auditor, dan jasa non audit. Semakin lama berhubungan dengan klien dan semakin tingginya tekanan dari klien maka semakin rendah independensi dari auditor. Sedangkan peer review dan tidak diberikannya jasa non audit saat memberikan jasa audit akan meningkatkan independensi. Dengan tidak adanya intervensi dan hubungan dengan klien dan adanya review yang kuat di dalam tim audit maka akan menjaga kualitas dari audit yang diberikan. Dengan adanya independensi dari auditor maka dapat membuat prosedur audit, melaksanakan audit dan melaporkan hasil audit dengan baik sehingga menghasilkan kualitas audit yang tinggi (Waskito, 2016). Hasil penelitian (Dewa et al., 2019; Dewana, 2015; Dokman, 2020; Mutiara, 2018; Wardhatul et al., 2019) menyatakan bahwa independensi berpengaruh positif terhadap kualitas audit. Dari penjelasan di atas, disimpulkan hipotesis yaitu :

$\mathrm{H}_{2}$ : Independensi berpengaruh positif terhadap kualitas audit

Peran Kompetensi Auditor terhadap Kualitas Audit dengan Etika Auditor sebagai Variabel Moderasi
Kompetensi yang dimiliki oleh auditor baik dari pengetahuan maupun dari pengalaman membuat mereka mampu mendeteksi salah saji dalam laporan keuangan. Selain kompeten, seorang auditor juga harus memiliki etika yang tinggi. Mereka akan menjalankan tugas sesuai dengan rambu-rambu yang berlaku di kantor akuntan publik dan pada organisasi profesi. Sehingga adanya etika terhadap organisasi maka akan meningkatkan kualitas audit yang dihasilkan (Harjanto, 2014). Auditor wajib mematuhi kode etik profesi yang menyangkut aturan etika dan prinsip etika yang mengatur perilaku auditor dalam menjalankan praktik profesi baik dengan sesama anggota maupun dengan masyarakat umum. Hasil penelitian dari (Mutiara, 2018; Wardhatul et al., 2019) menyatakan bahwa etika auditor mampu mempengaruhi hubungan kompetensi terhadap kualitas audit. Berdasarkan penjelasan di atas, dapat disimpulkan hipotesis :

$\mathrm{H}_{3}$ : Etika auditor memperkuat hubungan kompetensi terhadap kualitas audit

\section{Peran Independensi terhadap Kualitas Audit dengan Etika Auditor sebagai Variabel Moderasi}

(Wardhani \& Astika, 2018) mengemukakan bahwa pada konflik kekuatan, klien dapat menekan auditor untuk melawan standar profesional dan dalam ukuran yang besar, kondisi keuangan klien dapat digunakan sebagai alat untuk menekan auditor. Bila seorang auditor melawan standar professional yang sudah ditetapkan, maka kualitas audit yang akan dihasilkan akan tergolong lemah. Namun, dengan etika yang baik, seorang auditor akan menaati standar profesional meskipun berada di bawah tekanan. Auditor yang bersifat independen dan memiliki etika yang tinggi maka akan mampu meningkatkan kualitas audit. Hasil penelitian dari (Nurjanah \& Kartika, 2016) dan (Dokman, 2020) menyatakan bahwa etika auditor mampu mempengaruhi hubungan independensi terhadap kualitas audit. Berdasarkan uraian pernyataan di atas, maka disimpulkan hipotesis:

$\mathrm{H}_{4}$ : Etika auditor memperkuat hubungan independensi terhadap kualitas audit

\section{METODE PENELITIAN}

Populasi dalam penelitian ini adalah seluruh auditor yang bekerja pada KAP di Bali yang 
sampling.

Tabel 1

Daftar Sampel Jumlah Auditor

\begin{tabular}{|l|c|}
\hline Populasi & 13 KAP \\
\hline Jumlah Auditor Keseluruhan & 102 Orang \\
\hline $\begin{array}{l}\text { Jumlah auditor dengan pengalaman kerja kurang dari } \\
1 \text { Tahun }\end{array}$ & (9 Orang) \\
\hline Jumlah sampel yang digunakan & $\mathbf{9 3}$ Orang \\
\hline
\end{tabular}

Definisi dari masing-masing variabel dijelaskan penelitian Aprianti (2010) dengan menggunakan sebagai berikut:

1) Kompetensi Auditor (KP)

Kompetensi merupakan pengetahuan, keahlian dan pengalaman yang dibutuhkan auditor dalam melakukan audit secara obyektif. Pernyataan dalam kuesioner diadopsi dari penelitian Aprianti (2010) dengan menggunakan indikator pengetahuan dan psikologi.

2) Independensi (IND)

Independensi merupakan sikap bebas dan tidak mempunyai kepentingan pribadi. Independensi diukur dengan menggunakan pernyataan yang menggambarkan tingkat persepsi auditor terhadap keleluasaan yang dimiliki dalam melakukan audit. Kuesioner dalam penelitian ini diadopsi dari indikator lama hubungan dengan klien, tekanan dari klien, telaah dari rekan auditor, dan jasa non audit.

3) Etika auditor (EA)

Kode etik auditor ialah aturan perilaku seorang auditor berdasarkan tuntutan profesi dan organisasi profesi serta standar audit yang merupakan ukuran mutu minimal yang wajib dipenuhi oleh auditor dalam menjalankan tugas auditnya. Dalam penelitian ini, kuesioner berdasarkan penelitian Sari (2018). Indikator yang digunakan adalah tanggung jawab profesi auditor, integritas dan objektivitas.

Teknik analisis data yang digunakan adalah Moderated Regression Analysis (MRA) dengan model penelitian adalah sebagai berikut:

\section{Gambar 1}

\section{Model Penelitian}

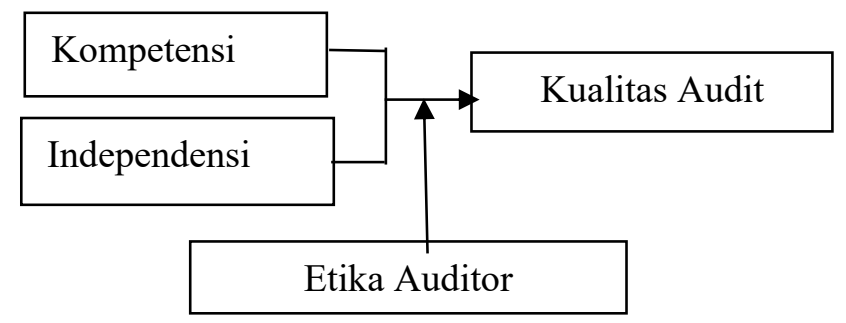

\section{HASIL DAN PEMBAHASAN \\ Deskripsi Responden}

Tabel 2

Data Pendistribusian Kuesioner

\begin{tabular}{|l|l|c|c|c|}
\hline So & \multicolumn{1}{|c|}{ Nama Kap } & $\begin{array}{c}\text { Kuesioner } \\
\text { disebar }\end{array}$ & $\begin{array}{c}\text { Kuesioner } \\
\text { Kembali }\end{array}$ & $\begin{array}{c}\text { Kuesioner } \\
\text { digunakan }\end{array}$ \\
\hline $\begin{array}{l}\text { KAP Arnaya \&Darmayasa } \\
\text { mat: Jalan Cargo Indah III A Perum Melanghill } \\
\text { No. 1, Ubung, Denpasar }\end{array}$ & 2 & 2 & 2 \\
\hline $\begin{array}{l}\text { KAP BudhanandaMunidewi } \\
\text { Alamat: Jalan Tukad Irawadi No. 18A, Panjer, }\end{array}$ & 5 & 5 & 5 \\
\hline
\end{tabular}




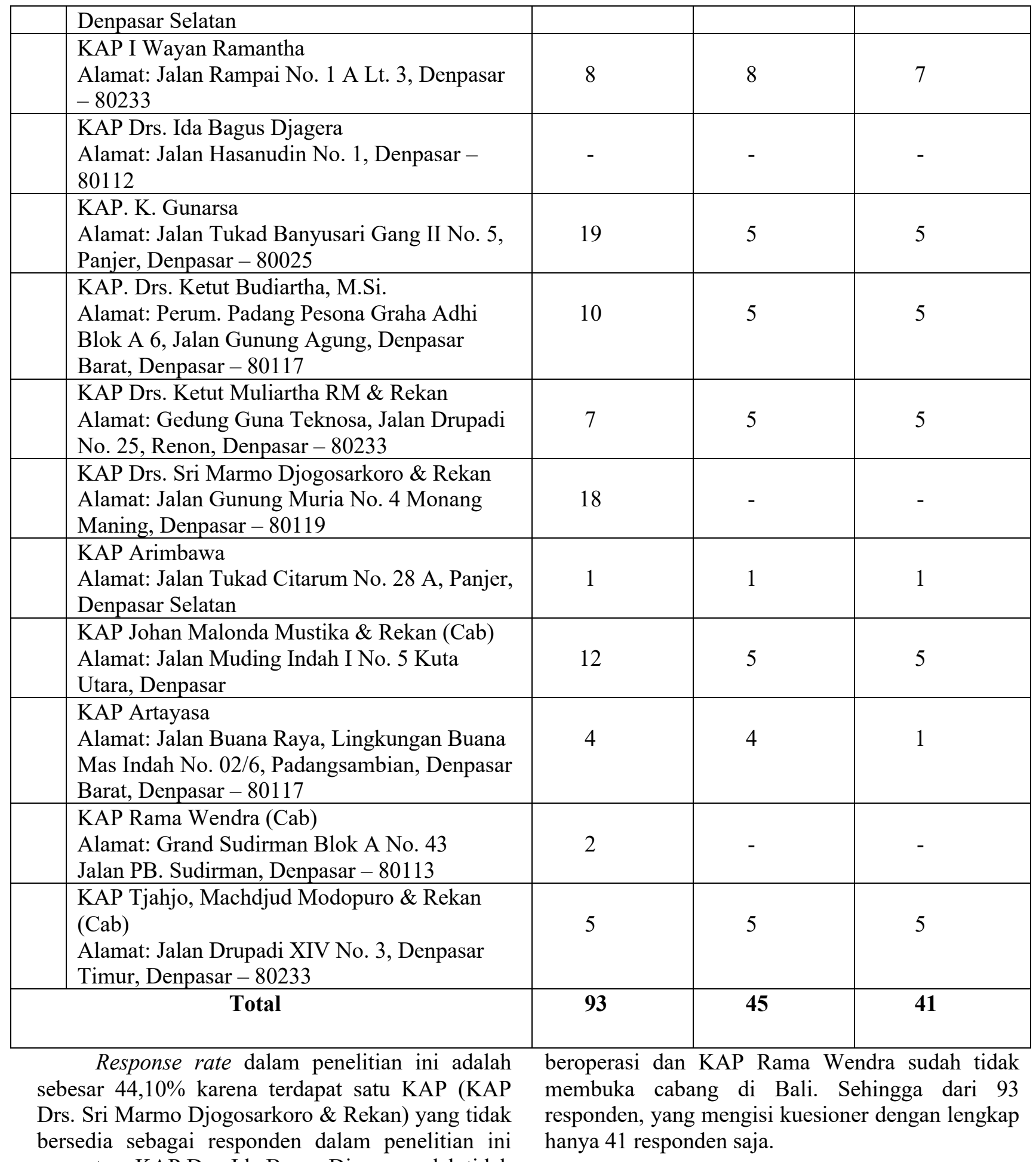

sementara KAP Drs. Ida Bagus Djagera sudah tidak 
Tabel 3

Karakteristik Responden Berdasarkan Jenis Kelamin

\begin{tabular}{|c|c|c|}
\hline Jenis Kelamin & Jumlah (Orang) & Persentase (\%) \\
\hline Laki-laki & 12 & 29,27 \\
\hline Perempuan & 29 & 70,73 \\
\hline Total & $\mathbf{4 1}$ & $\mathbf{1 0 0}$ \\
\hline
\end{tabular}

Berdasarkan tabel tersebut, responden dalam penelitian ini didominasi oleh perempuan dengan rincian responden laki-laki sebanyak 12 orang

$(29,27 \%)$ dan responden perempuan sebanyak 29 orang $(70,73 \%)$.

Tabel 4

Karakteristik Responden Berdasarkan Usia

\begin{tabular}{|c|c|c|}
\hline Usia & Jumlah (Orang) & Persentase (\%) \\
\hline$<30$ & 37 & 90,2 \\
\hline $31-40$ & - & - \\
\hline $41-50$ & 2 & 4,9 \\
\hline$>50$ & 2 & 4,9 \\
\hline Total & $\mathbf{4 1}$ & $\mathbf{1 0 0}$ \\
\hline
\end{tabular}

Berdasarkan tabel diatas, responden sebagian besar berusia kurang dari 30 tahun yaitu sebanyak 37 orang $(90,2 \%)$, tidak ada responden yang berusia 31 hingga 40 tahun, kemudian terdapat 2 orang responden dengan rentang usia 41 hingga 50

tahun $(4,9 \%)$ dan 2 orang lainnya berusia di atas 50 tahun $(4,9 \%)$. Dari data diatas dapat diketahui bahwa dominan auditor yang bekerja di KAP masih tergolong muda.

Tabel 5

Karakteristik Responden Berdasarkan Tingkat Pendidikan

\begin{tabular}{|c|c|c|}
\hline Pendidikan Terakhir & Jumlah (Orang) & Persentase (\%) \\
\hline SMA / Diploma & 1 & 2,45 \\
\hline S1 & 34 & 82,95 \\
\hline S2 & 6 & 14,6 \\
\hline S3 & - & - \\
\hline Total & $\mathbf{4 1}$ & $\mathbf{1 0 0}$ \\
\hline
\end{tabular}

Profil tingkat pendidikan digunakan untuk kemudian dengan tingkat pendidikan S1 sebanyak mengetahui tingkat intelektualitas responden 34 orang $(82,95 \%)$, dilanjutkan dengan responden sebagai auditor. Berdasarkan tabel dapat diketahui yang memiliki tingkat pendidikan hingga S2 bahwa responden dengan tingkat pendidikan sebanyak 6 orang $(14,6 \%)$, dan tidak adanya SMA/Diploma sebanyak 1 orang $(2,45 \%)$, responden yang menempuh pendidikan S3. 
Tabel 6

Karakteristik Responden Berdasarkan Lama Bekerja

\begin{tabular}{|c|c|c|}
\hline Lama Bekerja & Jumlah (Orang) & Persentase (\%) \\
\hline $1-2$ tahun & 17 & 41,5 \\
\hline $2-4$ tahun & 14 & 34,1 \\
\hline$>4$ tahun & 10 & 24,4 \\
\hline Total & $\mathbf{4 1}$ & $\mathbf{1 0 0}$ \\
\hline
\end{tabular}

Berdasarkan tabel diatas, dapat disimpulkan bahwa pengalaman kerja didominasi oleh responden dengan pengalaman kerja 1 hingga 2 tahun terdiri atas 17 orang $(41,5 \%)$, kemudian responden dengan pengalaman kerja antara 2 hingga 4 tahun sebanyak 14 orang $(34,1 \%)$ dan

Tabel 7

Karakteristik Responden Berdasarkan Jabatan

\begin{tabular}{|c|c|c|}
\hline Jabatan & Jumlah (Orang) & Persentase (\%) \\
\hline Auditor senior & 29 & 70,73 \\
\hline Auditor junior & 9 & 21,95 \\
\hline Manajer & 1 & 2,44 \\
\hline Partner & 1 & 2,44 \\
\hline Supervisor & 1 & 2,44 \\
\hline Total & $\mathbf{4 1}$ & $\mathbf{1 0 0}$ \\
\hline
\end{tabular}

Berdasarkan tabel diatas, dapat diketahui manajer sebanyak 1 orang $(2,44 \%)$, dilanjutkan bahwa responden dengan jabatan auditor senior dengan responden yang memiliki jabatan sebanyak 29 orang $(70,73 \%)$, responden partner sebanyak 1 orang $(2,44 \%)$ dan dengan jabatan auditor junior sebanyak 9 orang responden dengan jabatan supervisor sebanyak $(21,95)$, kemudian responden dengan jabatan 1 orang $(2,44 \%)$

Tabel 8

\section{Uji Koefisien Determinasi}

\begin{tabular}{|l|c|r|c|c|}
\multicolumn{7}{|c|}{ Model Summary } \\
\hline Model & $\mathrm{R}$ & $\mathrm{R}$ Square & $\begin{array}{c}\text { Adjusted } \\
\text { R Square }\end{array}$ & $\begin{array}{c}\text { Std. Error of } \\
\text { the Estimate }\end{array}$ \\
\hline 1 & $.800^{\mathrm{a}}$ & .639 & .588 & 1.92196 \\
\hline
\end{tabular}

Setelah memenuhi syarat dari uji instrument (uji validitas dan uji reliabilitas) serta uji asumsi klasik maka pengujian dapat dilanjutkan ke tahap berikutnya. Berdasarkan hasil tabel diatas, nilai
Adjusted $R^{2}$ sebesar 0,588 yang berarti sebesar 58,8 persen variasi dari variabel dependen mampu dijelaskan oleh variabel karakter auditor yaitu kompetensi dan independensi. 
Tabel 9

Moderated Regression Analysis

\begin{tabular}{|c|c|c|c|c|c|c|c|c|}
\hline \multirow[b]{2}{*}{ Model } & & \multicolumn{2}{|c|}{$\begin{array}{l}\text { Unstandardized } \\
\text { Coefficients }\end{array}$} & \multirow{2}{*}{$\begin{array}{c}\begin{array}{c}\text { Standardized } \\
\text { Coefficients }\end{array} \\
\text { Beta }\end{array}$} & \multirow[b]{2}{*}{$t$} & \multirow[b]{2}{*}{ Sig. } & \multicolumn{2}{|c|}{ Collinearity Statistics } \\
\hline & & B & Std. Error & & & & Tolerance & VIF \\
\hline & (Constant) & 18.326 & 5.628 & & 3.256 & .003 & & \\
\hline & $\mathrm{KP}$ & .036 & .017 & .347 & 2.112 & .042 & .382 & 2.614 \\
\hline & IND & .046 & .070 & .083 & .656 & .516 & .637 & 1.571 \\
\hline & EA & .580 & .258 & .630 & 2.254 & .031 & .132 & 7.574 \\
\hline & KP*EA & .000 & .003 & .021 & .067 & .947 & .105 & 9.554 \\
\hline & IND*EA & -.003 & .003 & -207 & -1.202 & .238 & .346 & 2.891 \\
\hline
\end{tabular}

Berdasarkan tabel diperoleh persamaan regresi berikut :

$\mathrm{KA}=18,326+0,036 \mathrm{KP}+0,046 \mathrm{IND}+0,580 \mathrm{EA}+$ $0,000(\mathrm{KP} * \mathrm{EA})-0,003$ (IN*EA)

\section{Pengaruh Kompetensi terhadap Kualitas audit}

Hipotesis pertama menyatakan bahwa kompetensi berpengaruh positif terhadap kualitas audit. Berdasarkan pengujian yang dilakukan, diperoleh hasil bahwa kompetensi berpengaruh positif terhadap kualitas audit dengan nilai koefisien regresi 0,036 dan signifikansi sebesar 0,042. Sehingga dapat disimpulkan bahwa semakin tinggi kompetensi seorang auditor maka kualitas audit yang dihasilkan juga akan semakin baik. Apabila auditor mempunyai tingkat kompetensi yang baik, maka auditor akan lebih mudah dalam melaksanakan tugas-tugas auditnya dan sebaliknya, jika tingkat kompetensinya rendah maka dalam melaksanakan tugasnya, auditor akan kesulitan yang menyebabkan kualitas audit yang dihasilkan juga rendah

\section{Pengaruh Independensi terhadap Kualitas Audit}

Hipotesis kedua menyatakan bahwa independensi berpengaruh positif terhadap kualitas audit. Berdasarkan pengujian yang dilakukan, diperoleh hasil bahwa independensi tidak berpengaruh terhadap kualitas audit dengan nilai signifikansi sebesar 0,516. Tekanan dari klien agar hasil audit sesuai dengan harapan klien dapat menyebabkan independensi seorang auditor lemah sehingga mempengaruhi kualitas audit. Namun dengan adanya review dalam tim audit, dapat mengurangi resiko lemahnya kualitas audit walaupun terdapat auditor yang tidak independen.

Pengaruh Kompetensi Terhadap Kualitas Audit dengan Etika Auditor sebagai Variabel

\section{Moderasi}

Hipotesis ketiga menyatakan bahwa etika auditor memperkuat hubungan kompetensi terhadap kualitas audit. Berdasarkan pengujian yang dilakukan, diperoleh hasil bahwa etika auditor ternyata tidak dapat memperkuat atau memperlemah hubungan kompetensi terhadap kualitas audit dengan nilai signifikansi sebesar 0,947. Kompetensi yang rendah menghasilkan kualitas audit yang juga rendah dengan ada atau tidaknya etika. Hal tesebut dikarenakan, meski seorang auditor memiliki etika yang baik, namun jika tidak memiliki kompetensi yang tinggi, maka audit yang dihasilkan kurang maksimal karena kurang paham dan telitinya auditor dalam melakukan review terhadap laporan keuangan klien.

\section{Pengaruh Independensi Terhadap Kualitas Audit dengan Etika Auditor sebagai Variabel Moderasi}

Hipotesis keempat menyatakan bahwa etika auditor memperkuat hubungan kompetensi terhadap kualitas audit. Berdasarkan penelitian yang dilakukan, diperoleh hasil bahwa etika auditor ternyata tidak dapat memperkuat atau memperlemah hubungan independensi terhadap kualitas audit dengan nilai signifikansi sebesar 0,238. Menurut Putranto (2018), seorang auditor dalam menjalankan tugasnya diwajibkan untuk berpedoman pada kode etik. Kode etik merupakan suatu hal yang wajib dilakukan oleh auditor. Sehingga dapat disimpulkan bahwa sebagian auditor ada yang melanggar kode etik dalam bekerja karena mendapat tekanan dari klien untuk mengikuti semua keinginan klien dengan memberikan hadiah yang dapat memperlemah independensi auditor. Namun lemahnya independensi auditor dapat diatasi dengan adanya 
reiew dalam tim audit sehingga kualitas audit dapat

\section{KESIMPULAN DAN SARAN}

Berdasarkan hasil analisis dalam penelitian ini, dapat diambil kesimpulan sebagai berikut:

1. Kompetensi berpengaruh positif terhadap kualitas audit. Hal tersebut menunjukan bahwa semakin meningkat kompetensi seorang auditor, maka kualitas audit yang dihasilkan semakin baik.

2. Independensi tidak berpengaruh terhadap kualitas audit. Hal tersebut menunjukan bahwa semakin tinggi atau rendah independensi seorang auditor, tidak dapat mempengaruhi kualitas audit yang dihasilkan, karena adanya review dalam tim audit.

3. Etika Auditor tidak mampu memoderasi hubungan antara kompetensi dengan kualitas audit. Kompetensi yang rendah menghasilkan kualitas audit yang juga rendah dengan ada atau tidaknya etika. Hal tesebut dikarenakan, meski seorang auditor memiliki etika yang baik, namun jika tidak memiliki kompetensi yang tinggi, maka audit yang dihasilkan kurang maksimal karena kurang paham dan telitinya auditor dalam melakukan review terhadap laporan keuangan klien. terjaga.

4. Etika Auditor tidak mampu memoderasi hubungan antara independensi dengan kualitas audit. Hal tersebut dikarenakan responden dalam penelitian ini memiliki rentang usia kurang dari 30 tahun dan memiliki masa jabatan didominasi antara satu hingga dua tahun. Dalam rentang usia dan masa jabatan yang terbilang baru tersebut, independensi auditor masih dianggap lemah sehingga memungkinkan terjadinya penyimpangan kode etik dalam menjalankan tugasnya. Namun kualitas audit masih dapat terjaga karena adanya review dalam tim audit.

Dari hasil penelitian ini maka diharapkan bagi KAP untuk meningkatkan kualitas auditnya wajib memperhatikan faktor kompetensi dari auditor karena dengan kompetensi yang dimiliki akan mampu mendeteksi salah saji dalam laporan keuangan. Selain itu rendahnya response rate dalam penelitian dapat diatasi dengan menambah batasan waktu dalam penyebaran kuesioner maupun melakukan pendampingan dalma pengisian kuesioner.

\section{DAFTAR PUSTAKA}

Abdelmoula, L. (2020). Impact of auditor's competence, independence and reputation on the jointaudit quality: The Tunisian context. Academy of Accounting and Financial Studies Journal.

Modeling.

Jensen, N., \& Meckling, W. (1976). Theory of the firm: Managerial behavior, agency costs, and capital structure. Journal of Financial Economics.

Dewa, I., Pratiwi, A. D., Nyoman, N., Suryandari, A., Anak, D., Mutiara, I. (2018). PENGARUH KOMPETENSI DAN Putu, A., Bagus, G., \& Susandya, A. (2019). Peran Independensi, Tekanan Waktu, Kompleksitas Tugas, dan Pengalaman Auditor Terhadap Kualitas Audit. In Jurnal Bisnis dan Akuntansi.

INDEPENDENSI AUDITOR TERHADAP KUALITAS AUDIT DENGAN ETIKA AUDITOR SEBAGAI VARIABEL MODERASI. JURNAL RISET AKUNTANSI JAMBI. https://doi.org/10.35141/jraj.v1i2.60

Dewana, G. A. (2015). Pengaruh independensi, kompetensi, fee Nurjanah, I. B., \& Kartika, A. (2016). Pengaruh Kompetensi, audit terhadap kualitas audit dengan etika audit sebagai variabel moderating. Jurnal Bisnis Manajemen Dan Ekonomi.

Dokman, D. M. S. E. B. S. (2020). PENGARUH KOMPETENSI DAN INDEPENDENSI AUDITOR TERHADAP KUALITAS AUDIT DENGAN ETIKA AUDITOR SEBAGAI VARIABEL MODERATING PADA KANTOR AKUNTAN PUBLIK DI KOTA MEDAN. Jurnal Ilmiah Akuntansi Dan Finansial Indonesia. https://doi.org/10.31629/jiafi.v3i2.2201

Farida, I., Halim, A., \& Wulandari, R. (2016). Pengaruh Independensi, Kompetensi, Due Professional Care, dan Etika terhadap Kualitas Audit (Studi Empiris pada KAP di Kota Malang). Jurnal Riset Mahasiswa Akuntansi Unikama.

IAPI. (2020). Directory 2020 (Kantor Akuntan Publik dan Independensi, Etika, Pengalaman Auditor, Skeptisme Profesional Auditor, Objektifitas dan Integritas Terhadap Kualitas Audit. Dinamika Akuntansi, Keuangan Dan Perbankan.

Wardhani, A. A. I. T. W., \& Astika, I. B. P. (2018). Pengaruh Kompetensi, Akuntabilitas dan Independensi pada Kualitas Audit dengan Etika Auditor Sebagai Variabel Moderasi. EJurnal Akuntansi. https://doi.org/10.24843/eja.2018.v23.i01.p02

Wardhatul, A., In, K., \& Asyik, N. F. (2019). PENGARUH KOMPETENSI DAN INDEPENDENSI TERHADAP KUALITAS AUDIT DENGAN ETIKA AUDITOR SEBAGAI VARIABEL PEMODERASI Sekolah Tinggi Ilmu Ekonomi Indonesia (STIESIA) Surabaya. In Jurnal Ilmu dan Riset Akuntansi (JIRA). Akuntan Publik). Journal of Chemical Information and 
